\title{
Avaliação teórico-experimental da influência da espessura de alvenaria na resistência ao fogo de sistemas verticais de vedação
}

\author{
Theoretical-experimental assessment of the influence of \\ masonry thickness on mansory fire resistance
}

\section{Guilherme Günther Hennemann \\ Augusto Masiero Gil \\ Bruno Fernandes \\ Fabrício Longhi Bolina \\ Bernardo Fonseca Tutikian}

\section{Resumo}

Guilherme Guinther Hennemann Universidade do Vale do Rio dos Sinos São Leopoldo - RS - Brasil

Augusto Masiero Gil Universidade do Vale do Rio dos Sinos São Leopoldo - RS - Brasil

Bruno Fernandes Universidade Estadual de Campinas Campinas - SP - Brasil

Fabrício Longhi Bolina Universidade do Vale do Rio dos Sinos São Leopoldo - RS - Brasil

Bernardo Fonseca Tutikian Universidade do Vale do Rio dos Sinos São Leopoldo - RS - Brasil

Recebido em 19/01/16 Aceito em 24/12/16

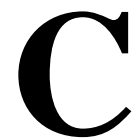

om a entrada em vigor da norma brasileira de desempenho das edificações habitacionais, a NBR 15575 (ABNT, 2013), alguns setores da indústria têm buscado avaliar, certificar e melhorar seus sistemas, de modo a atender aos requisitos praticados pela norma e garantir sua empregabilidade. Entre estes está o de vedação vertical composta de blocos cerâmicos. Dada a variabilidade da matéria-prima desses blocos, faz-se necessária uma análise mais detalhada de seu desempenho como sistema construtivo. Quanto aos requisitos de desempenho definidos pela norma para esses sistemas está o de resistência ao fogo. No entanto, no Brasil não há normas regulamentadoras para o projeto de paredes de alvenaria em situação de incêndio, sendo necessária a realização de ensaios para avaliar esse requisito. Este estudo teve como objetivo avaliar a resistência ao fogo de duas paredes, com espessuras de $14 \mathrm{~cm}$ e $19 \mathrm{~cm}$, acompanhando os critérios de estabilidade, estanqueidade e isolamento térmico pelo período de $240 \mathrm{~min}$. Os sistemas foram numericamente avaliados pelo método da Brick Industry Asssociation (BIA). Como resultados, na análise experimental os sistemas atenderam aos critérios de estabilidade e estanqueidade durante o período de ensaio, mas reprovaram no critério de isolamento térmico aos $60 \mathrm{~min}$ e $90 \mathrm{~min}$ para as paredes com espessura de $14 \mathrm{~cm}$ e $19 \mathrm{~cm}$ respectivamente. Quanto à análise teórica, constatou-se um tempo de resistência ao fogo (TRF) até $30 \%$ menor do que o obtido experimentalmente, o que enaltece o conservadorismo desse método.

Palavras-chave: Alvenaria. Desempenho. Segurança contra incêndios.

\section{Abstract}

After the Brazilian performance housing standard, NBR 15575 (ABNT, 2013) was introduced, various sectors of the industry sought to evaluate, certify and improve their systems in order to meet the requirements of the standard. Masonry walls are one type of these systems. The ceramic industry has blocks with different characteristics, which require a more detailed analysis. One of the performance requirements is fire resistance of this construction system, which is not covered by Brazilian standards. This study aimed to evaluate the fire resistance of two walls, consisting of blocks $14 \mathrm{~cm}$ and $19 \mathrm{~cm}$ thick, evaluating the criteria for structural stability, integrity and thermal insulation for a period of 240 min. In the experimental analysis, the systems fulfilled the criteria of stability and integrity satisfactorily throughout the test, but failed the thermal insulation criteria at 60 and 90 min for smaller and thicker walls respectively. Concerning the theoretical analysis, a fire resistance time was observed up to $30 \%$ lower than that obtained experimentally.

Keywords: Masonry. Performance. Fire safety. 


\section{Introdução}

Entre os requisitos dos usuários praticados pela norma de desempenho das edificações, a NBR 15575 (ABNT, 2013), destaca-se o de segurança ao incêndio, devendo ser cumprido ainda em projeto. Por seu caráter qualitativo, a NBR 15575 (ABNT, 2013) se reporta às normas prescritivas para que seus requisitos sejam atendidos, como a NBR 14432 (ABNT, 2001).

Na prática de projeto a NBR 14432 (ABNT, 2001) apresenta as exigências de resistência ao fogo de elementos construtivos de edificações, estabelecendo o chamado tempo requerido de resistência ao fogo (TRRF), definido em função da altura e uso da edificação. Segundo Silva (2012), o TRRF é o período em que um sistema, com ou sem função estrutural, deve preservar as características de estabilidade, estanqueidade e isolamento térmico quando exposto a altas temperaturas. $\mathrm{O}$ estudo da resistência ao fogo dos sistemas construtivos se concentra no período pós-fashover e se faz necessário para garantir a integridade da edificação durante o incêndio. Nesse estágio os sistemas de vedação vertical passam a interagir com as chamas, o que conduz a alterações das propriedades dos materiais que o constituem, principalmente a resistência mecânica (COSTA; SILVA, 2006).

Materiais cerâmicos são amplamente empregados na construção civil por diversas razões, entre elas o desempenho satisfatório ao fogo, devido a sua propriedade incombustível (ROMAN, 1991). Essa característica, aliada à baixa condutividade térmica, faz com que sistemas tenham capacidade de apresentar boa resistência ao fogo (INGHAM, 2009). Sinistros históricos e ensaios laboratoriais reforçam o bom desempenho desse material quando submetido a altas temperaturas (RUSSO; SCIARRETTA, 2012), uma vez que alterações físicas, químicas e mecânicas são inerentes a esse material (INGHAM, 2009).

Por outro lado, o estudo do comportamento das paredes de alvenarias é complexo, dadas as diversas combinações de blocos, juntas, geometrias e texturas possíveis de ser usados nesses sistemas (RUSSO; SCIARRETTA, 2012). Esses fatores tornam o estabelecimento de leis e modelos de previsão uma tarefa complexa (ANDREINI et al., 2015) e dificultam a extrapolação de resultados experimentais obtidos para outras configurações destes (NGUYEN et al., 2009), repercutindo num reduzido número de referências e normas regulamentadoras no assunto. Dentro desse cenário, o estudo de alvenaria em situação de incêndio apresenta maior necessidade de investigação.
No Brasil, apesar de sua ampla utilização (ROSEMANN, 2011), poucos estudos foram desenvolvidos no intuito de compreender e melhorar o comportamento desse sistema durante e após a exposição a altas temperaturas. Esse fato repercute na inexistência de normas regulamentadoras para projeto de sistemas em uma situação de incêndio. A Instrução Técnica n ${ }^{\circ} 08$ do Corpo de Bombeiros do Estado de São Paulo (SÃO PAULO, 2011) apresenta recomendações de TRRF para diferentes geometrias e tipos de blocos, mas sem mencionar as alvenarias sem revestimento nem as espessuras de $14 \mathrm{~cm}$ e $19 \mathrm{~cm}$, limitando, assim, o projeto de segurança contra incêndio.

Entre os estudos já realizados destacam-se pesquisas de Chichierchio (1990), Thomaz e Helene (2000), Klein et al. (2004), Rosemanm (2011) e Rigão (2012), sempre em amostras reduzidas. São necessários, portanto, estudos que visem avaliar o comportamento desse tipo de sistema e suas variações quando expostos a altas temperaturas, em escala real, de modo a auxiliar no desenvolvimento de modelos de dimensionamento adequados e compará-los com modelos já existentes, para contribuir com a prática de projeto do setor e a coletânea do estudo do desempenho dos materiais e sistemas construtivos nacionais.

Este estudo objetiva-se na verificação da influência da espessura da alvenaria na resistência ao fogo de sistemas de vedação vertical internos e externos, utilizando dois tipos de blocos cerâmicos de vedação, com espessuras de $14 \mathrm{~cm}$ e $19 \mathrm{~cm}$. As juntas horizontais e verticais, de $1,0 \mathrm{~cm}$ de espessura, são constituídas de argamassa composta de cimento, cal, areia e água, de traço 1:1:8:0,6, em massa, com 28 dias de cura à temperatura ambiente, tal como realizado na prática da construção. De modo a avaliar uma condição crítica, não foi empregado revestimento nas faces externas ou internas. A avaliação experimental foi feita em ensaios de resistência ao fogo de acordo com as prescrições das principais normas de ensaio, como a NBR 10636 (ABNT, 1989), E 119 (AMERICAN..., 2014), AS 1530 (AUSTRALIAN..., 2005) e BS 476-3 (BRITISH..., 2004), com exposição da curva padrão de temperatura da ISO 834-8 (INTERNATIONAL..., 2014), verificando os parâmetros de isolamento térmico, estabilidade estrutural e estanqueidade do sistema, necessário para garantir o requisito de compartimentação desse sistema, de forma a determinar seu tempo de resistência ao fogo (TRF). No Brasil a NBR 10636 (ABNT, 1989) classifica as amostras como corta-fogo (CF),

184 Hennemann, G. G.; Gil, A. M.; Fernandes, B.; Bolina, F. L.; Tutikian, B. F. 
quando se cumprem os requisitos de estabilidade, estanqueidade e isolamento térmico, ou como para-chamas (PC), quando mantém as características de estabilidade e estanqueidade durante o tempo de ensaio.

A avaliação teórica foi realizada mediante utilização do método proposto pelo Tchnical Note 16 (BRICK..., 2008) da Brick Industry Asssociation (BIA), no qual foi possível estimar o TRF desse sistema e compará-lo com o obtido experimentalmente.

\section{Alvenarias em situação de incêndio}

Os fatores que controlam o comportamento de paredes de alvenaria em elevadas temperaturas estão relacionados tanto às propriedades constitutivas do sistema quanto às características construtivas dos materiais que o compõem. Em relação aos materiais (blocos, argamassa de assentamento e de revestimento), sua natureza, as dimensões e a umidade interna afetam seu comportamento. Em escala global, as características dimensionais, vinculações e condições de carregamento também influenciam (NADJAI; O'GARRA; ALI, 2003; ANDREINI et al., 2015).

Em um incêndio uma parede de compartimentação é submetida a um gradiente térmico diferencial entre a face exposta às elevadas temperaturas e a não exposta (Figura 1a), criando um aquecimento diferencial na parede. A temperatura alcançada na face não exposta depende da resistência térmica da alvenaria, definida em função da forma de transferência de calor. Segundo Rosemann (2011), os blocos cerâmicos geralmente possuem perfurações ou vazios que influenciam na forma como o calor é transferido entre as faces. Nas partes maciças dos blocos o calor é transferido por condução, enquanto nos vazios a transferência ocorre por radiação, conforme ilustrado na Figura 1b (AL-HADHRAMI; AHMAD, 2009).

Destaca Rigão (2012) que a condutividade térmica do sistema dependerá fundamentalmente da densidade dos materiais componentes, e blocos cerâmicos com maior densidade, ou seja, menor índice de vazios apresentam valores mais elevados de condutividade térmica. Nesse caso, o aumento da temperatura provoca aumento da condutividade térmica dos materiais, mas diminui a transferência de calor por radiação. A presença de umidade aumenta a capacidade de transferência de calor por condução no material, uma vez que a água possui condutividade térmica maior que a do ar (ROSEMANN, 2011).

De maneira geral, blocos cerâmicos apresentam bom comportamento ante altas temperaturas, por seu baixo valor de condutividade térmica, de cerca de $0,25 \mathrm{~W} / \mathrm{mK}$. Esse bom comportamento faz com que alvenarias de blocos cerâmicos mantenham sua resistência mecânica em temperaturas de até $1.000{ }^{\circ} \mathrm{C}$, o que pode estar relacionado com o fato de os blocos já serem expostos às mesmas condições em sua produção (LAWRENCE; GNANAKRISHNAN, $1987^{1}$ apud AYALA, 2011). Para temperaturas maiores que $1.000^{\circ} \mathrm{C}$, os blocos cerâmicos podem vir a fundir (INGHAM, 2009).

Figura 1 - Esquema de (a) gradiente de temperatura em uma parede submetida a aquecimento em uma face; e (b) transferência de calor em um bloco

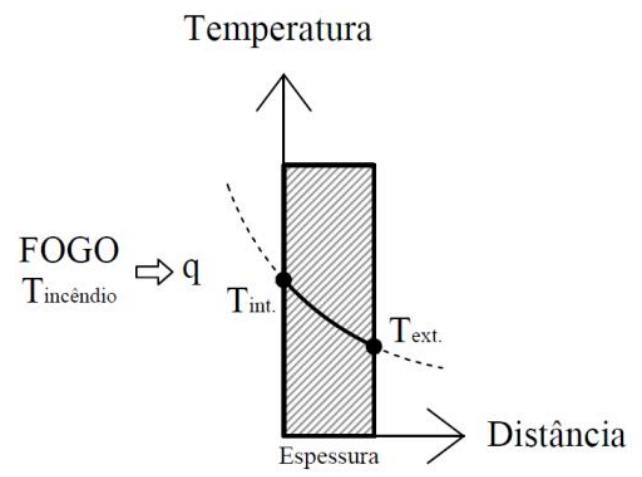

(a)

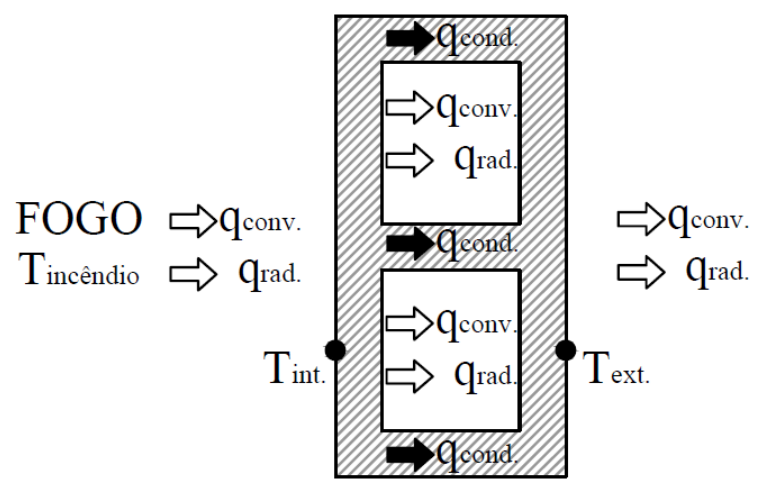

(b)

Fonte: adaptada de Rosemann (2011).

1LAWRENCE, S. J.; GNANAKRISHNAN, N. The Fire Resistance of Masonry Wallsan Overview. In: NATIONAL STRUCTURAL ENGINEERING CONFERENCE, Belbourne, 1987. Proceedings... Melbourne, 1987. 
No que se refere ao comportamento do sistema de alvenaria durante o aquecimento, verifica-se que este tende a deformar no sentido da face exposta ao fogo, porém, com o decorrer do tempo, recupera sua rigidez e reduz seu módulo de Young, retornando os deslocamentos ocorridos (NGUYEN et al., 2009). Esse comportamento é descrito por Rigão (2012) como o arqueamento da alvenaria (thermal bowing effect) e justificado pelo coeficiente de expansão térmica, vinculação, gradiente térmico, altura e espessura da parede analisada.

Outro importante fenômeno observado é o desplacamento ou lascamento (spalling). Esse fenômeno é mais conhecido nas estruturas de concreto, contudo também é recorrente em alvenarias, conforme apontado por Nguyen e Meftah (2012, 2014). Esse comportamento referese à desintegração de partes do bloco, sobretudo nas condições de baixa permeabilidade e umidade interna deste, que, sob uma alta taxa de aquecimento, criam pressões de vapores de água internas que, não dissipadas pela baixa permeabilidade do material, conduzem a sua desintegração, podendo ou não se dar de forma explosiva. O desplacamento afeta diretamente o comportamento mecânico das alvenarias, sobretudo na parte interna do bloco, exposta às maiores temperaturas, deformando a parede mais rapidamente e reduzindo a área resistente.

\section{Programa experimental}

\section{Materiais e amostras}

Os blocos cerâmicos utilizados na confecção das amostras possuem as dimensões apresentadas na Figura 2.

A argamassa utilizada para a confecção das juntas horizontais e verticais, com $1 \mathrm{~cm}$ de espessura, é composta de cimento CP II (10\%), cal hidratada $(10 \%)$ e areia média (80\%). Os blocos foram assentados com os furos na vertical, sem revestimento externo ou interno. As amostras foram confeccionadas em um pórtico móvel com as dimensões de $3.150 \times 3.000 \mathrm{~mm}$, sendo a superfície de $2.500 \times 2.500 \mathrm{~mm}$ exposta às chamas. Os sistemas são compostos de 14 fiadas com blocos com furos no sentido vertical e uma fiada de blocos com furos no sentido horizontal, de modo a promover melhor fechamento do sistema no pórtico de ensaio. A Figura 3 apresenta a disposição dos blocos utilizados na composição de cada amostra, e a Figura 4 as amostras acopladas ao forno vertical.

\section{Análise experimental}

A análise dos sistemas produzidos foi realizada com um forno vertical seguindo os procedimentos de ensaio definidos na NBR 10636 (ABNT, 1989), E 119 (AMERICAN..., 2014), AS 1530 (AUSTRALIAN..., 2005) e BS 476 (BRITISH..., 2004), no Laboratório de Segurança contra Incêndio do Instituto Tecnológico em Desempenho e Construção Civil (itt Performance), da Universidade do Vale do Rio dos Sinos (Unisinos), em São Leopoldo, RS. Esse ensaio visa avaliar características de isolamento térmico, estanqueidade e estabilidade estrutural do sistema, determinando seu TRF e definindo sua limitação como sistema construtivo, conforme a NBR 14432 (ABNT, 2001).

Figura 2 - Características dimensionais dos blocos empregados na confecção das amostras

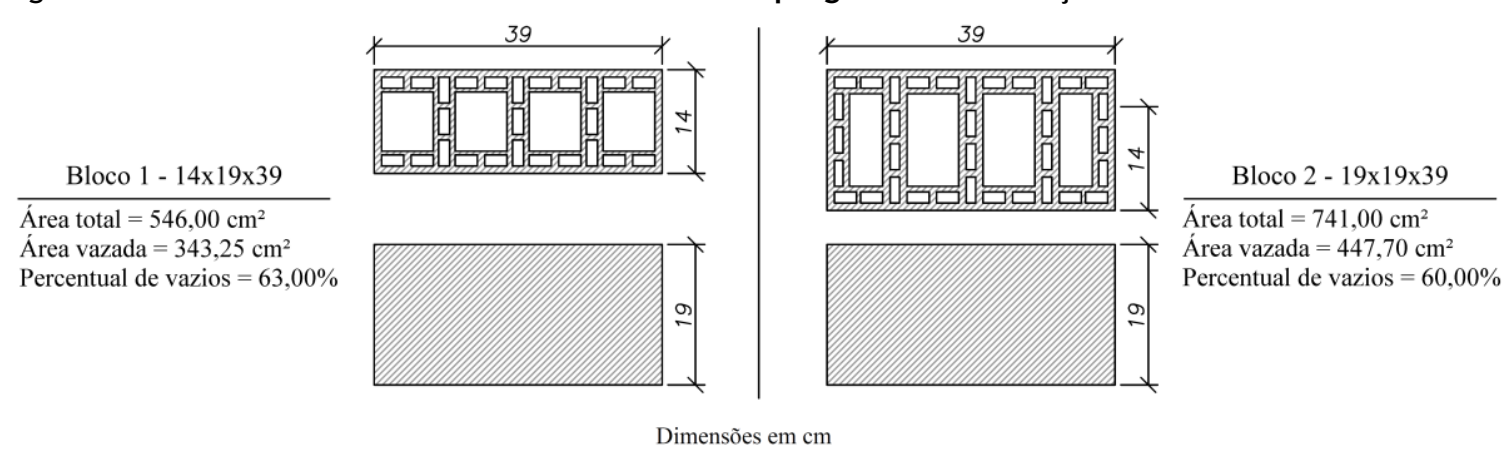

186 Hennemann, G. G.; Gil, A. M.; Fernandes, B.; Bolina, F. L.; Tutikian, B. F. 
Figura 3 - Composição das amostras utilizadas no ensaio de resistência ao fogo
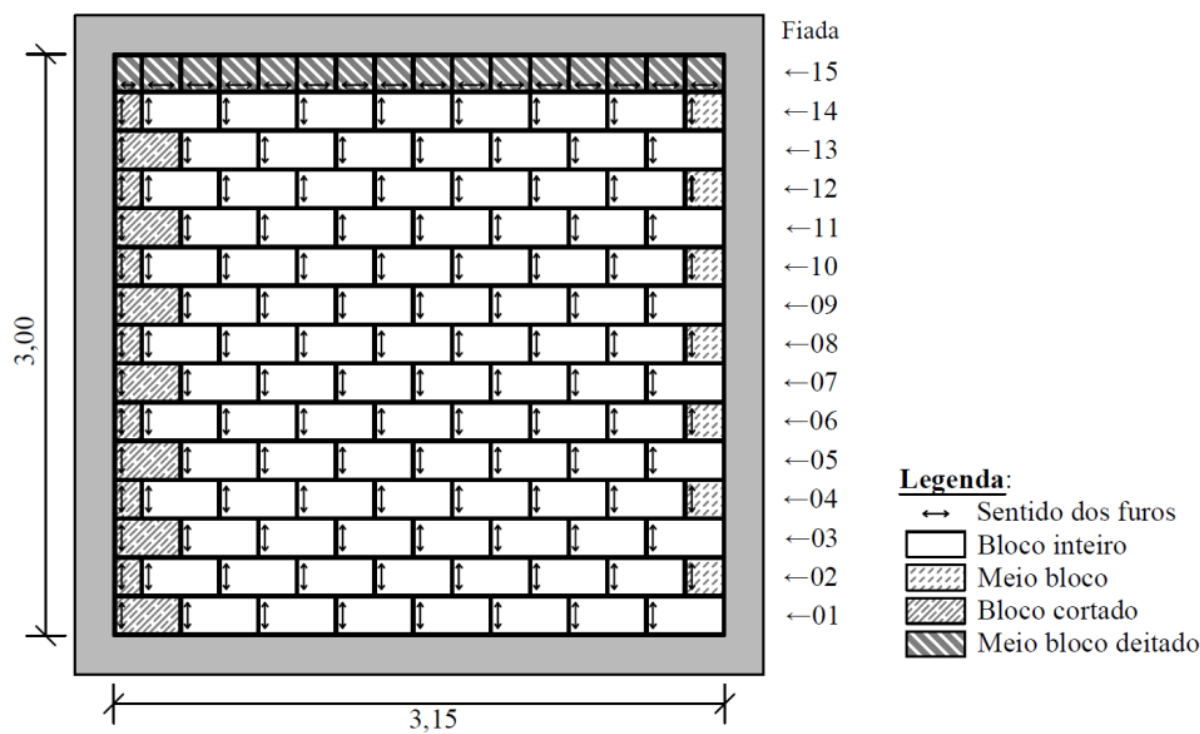

Figura 4 - Amostras acopladas ao forno vertical com espessura de: (a) $14 \mathrm{~cm}$, e (b) $19 \mathrm{~cm}$

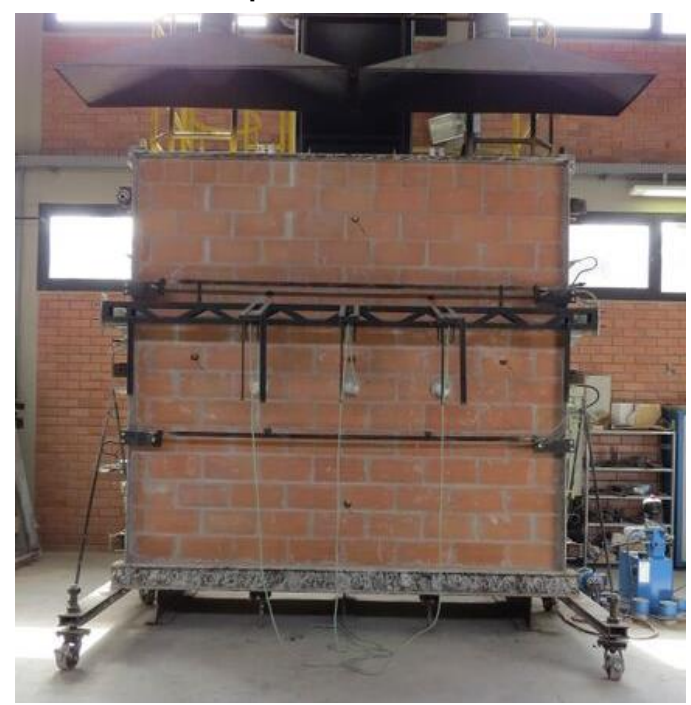

(a)

\section{Equipamentos}

Os ensaios de resistência ao fogo foram feitos em um forno vertical normatizado, com capacidade térmica de $1.200{ }^{\circ} \mathrm{C}$ e equipado com 4 queimadores alimentados por gás liquefeito de petróleo (GLP), programados para que o aumento da temperatura ocorra de acordo com a curva padronizada da ISO 834-8 (INTERNATIONAL..., 2014). Foi utilizada uma trena a laser para acompanhar as deformações horizontais no centro da amostra e câmera termográfica para auxiliar na identificação de fissuras que comprometessem a estanqueidade da amostra.

O forno é equipado com 14 termopares do tipo K, de diâmetro de $1,5 \mathrm{~mm}$, dos quais cinco são

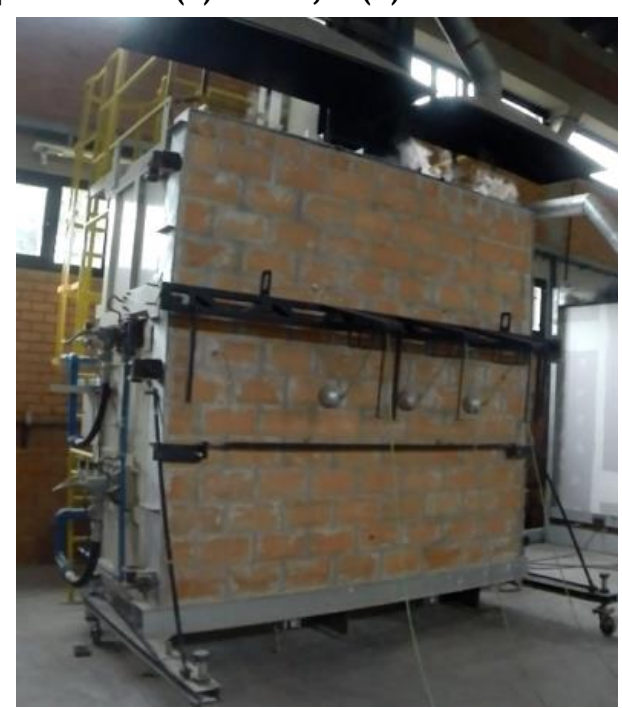

(b)

posicionados no interior do forno e nove na superfície externa da amostra. A Figura 5a apresenta a disposição dos termopares no interior do forno, numerados de 1 a 5 (TP01 a TP05). Na parte externa, do total de nove termopares, cinco foram dispostos na mesma locação dos termopares internos, sendo numerados de 6 a 10 (TP06 a TP10); e outros quatro adicionais foram numerados de 11 a 14 (TP11 a TP14), conforme apresentado na Figura 5b.

A Figura 6 detalha o forno vertical de grandes dimensões utilizados no ensaio e a disposição dos termopares internos.

O sistema de vedação foi construído em um pórtico móvel, o que facilita a montagem. Não foi 
empregado nenhum tipo de cura na amostra, tal como utilizado em obra, a qual foi ensaiada 28 dias depois de sua montagem. Na sequência, o pórtico móvel foi acoplado no forno vertical para a realização do ensaio.

\section{Procedimento de ensaio}

Durante o aquecimento, três verificações foram realizadas, isolamento térmico, estanqueidade e estabilidade, por serem estes os parâmetros que definem a capacidade de compartimentação de uma parede. A verificação do isolamento térmico consiste na análise das temperaturas registradas na face externa (não exposta diretamente a altas temperaturas) da amostra. Como limite as normas definem que a média aritmética dessas temperaturas não pode ser superior a $140{ }^{\circ} \mathrm{C}$ e ultrapassar $180{ }^{\circ} \mathrm{C}$ em nenhum dos termopares, acrescidos da temperatura ambiente do início do ensaio. Acima dessa temperatura, a vida no cômodo adjacente ao das chamas começa a ser prejudicado.

\section{Figura 5 - Disposição (a) interna e (b) externa dos termopares no forno}

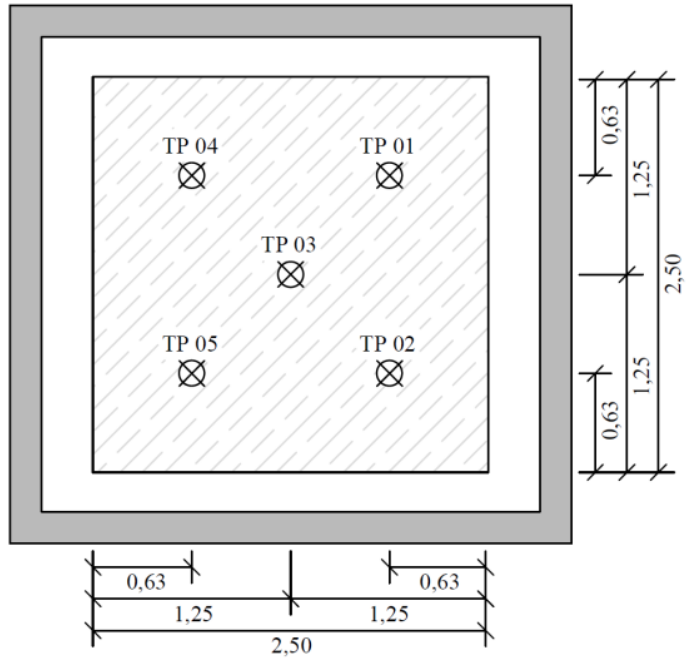

$\square$ Isolamento térmico do forno
$\square$ Face externa da amostra
$\square$ Face interna exposta
$\square$ Pórtico auxiliar de fixação da amostra

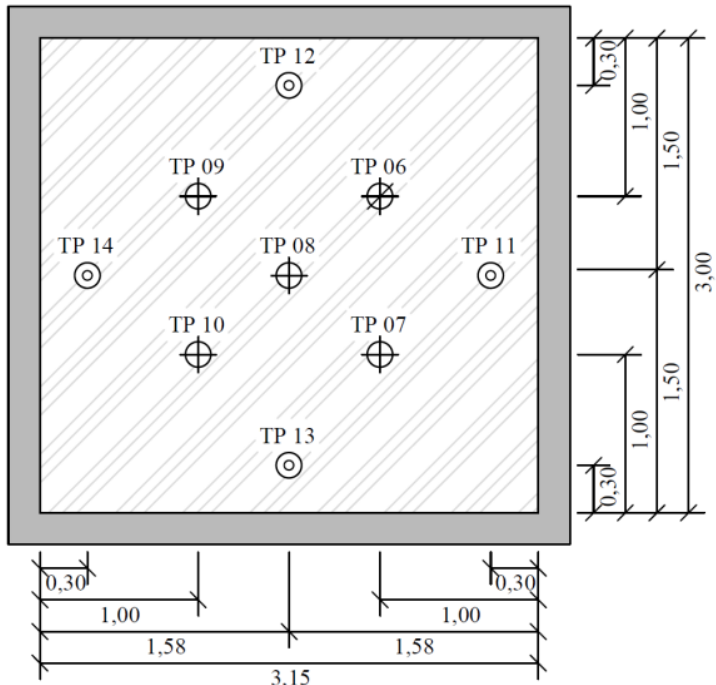

叉 Termopares internos

$\bigoplus$ Termopares externos principais

() Termopares externos extras

(a)

Dimensões em metros

Figura 6 - Detalhe (a) dos queimadores do forno e (b) da disposição dos termopares internos

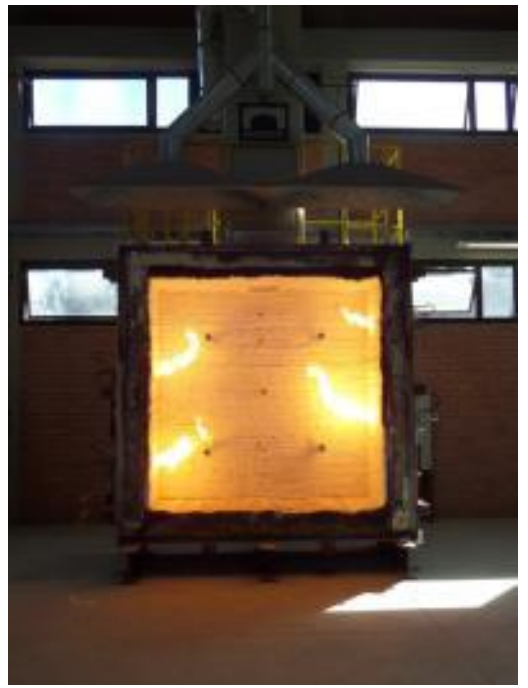

(a)

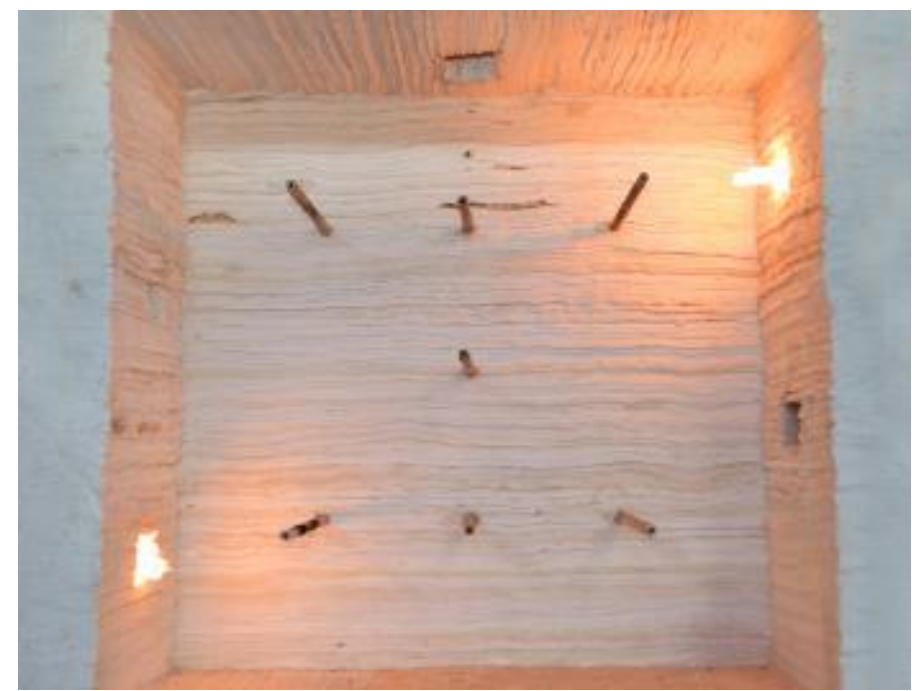

(b)

188 Hennemann, G. G.; Gil, A. M.; Fernandes, B.; Bolina, F. L.; Tutikian, B. F. 
A verificação da estanqueidade é realizada mediante o posicionamento de um chumaço de algodão, com uma haste metálica, próximo às fissuras deflagradas na amostra por $10 \mathrm{~s}$, respeitando-se uma distância de $1 \mathrm{~cm}$ a $3 \mathrm{~cm}$ e observando a flamabilidade dos gases (através da inflamação do algodão), que se dá em temperaturas próximas a $160{ }^{\circ} \mathrm{C}$, o que caracteriza a perda de estanqueidade da amostra por conduzir gases quentes ao cômodo adjacente.

A estabilidade estrutural é verificada através da aplicação do impacto mecânico de três esferas de aço, com massa de $25 \mathrm{~kg}$, alinhadas horizontalmente a uma distância de $1,40 \mathrm{~m}$ a partir da base da amostra, simulando objetos e corpos sendo arremessados na parede durante uma evacuação numa edificação em situação de incêndio. O impacto é realizado em movimento pendular, atingindo uma energia de 20 J. São analisadas deformações, trincas, possíveis colapsos ou sinais de instabilidade que possam comprometer a segurança dos usuários. De modo complementar, foram verificadas as deformações horizontais pela medição dos deslocamentos no centro da amostra.

A Figura 7 detalha o procedimento de verificação da estanqueidade e dos dispositivos para análise da estabilidade da amostra.

\section{Análise teórica}

A análise teórica efetuada consiste no cálculo da estimativa do TRF mediante o método proposto pelo Technical Note 16: Fire resistance of brick masonry da BIA. Esse método é baseado no critério de isolamento térmico e fornece uma estimativa rápida e simples do TRF (ROSEMANN, 2011).

O TRF consiste na determinação da espessura equivalente do sistema, incluindo todos os componentes dele. A espessura equivalente do bloco $\left(\mathrm{Ee}_{\text {bloco }}\right)$ é calculada em função do percentual de sólidos. A espessura equivalente do revestimento dependerá do tipo de argamassa e da face onde está localizada.

No caso de revestimentos externos (não expostos a altas temperaturas) o valor da espessura equivalente será o resultante da espessura da camada de revestimento multiplicado por um fator de correção, definido em função do tipo de material. No caso dos revestimentos internos a espessura será igual ao menor valor entre a espessura real da camada e o valor de 15,9 mm (BRICK..., 2008; ROSEMANN, 2011). As Equações 1 e 2 apresentam o cálculo da espessura.
$E e=E e_{\text {rev.interno }}+E e_{\text {bloco }}+E e_{\text {rev.externo }} \quad$ Eq. 1
$E e=E e_{\text {rev.interno }}+\left(E_{\text {bloco }} \times P_{s}\right)+\left(E e_{\text {rev.externo }} \times f\right)$ Eq. 2

Onde:

Ee: espessura equivalente $(\mathrm{mm})$;

$\mathrm{Ee}_{\text {rev.interno: espessura equivalente do revestimento }}$ interno (exposto ao fogo) ( $\mathrm{mm}$ );

Ee $_{\text {bloco: }}$ espessura equivalente do bloco $(\mathrm{mm})$;

$\mathrm{Ee}_{\text {rev.externo: espessura equivalente do revestimento }}$ externo (não exposto ao fogo) (mm);

$\mathrm{P}_{\mathrm{s}}$ : percentual de sólido; e

f: fator de correção para os revestimentos não expostos.

Após a definição da espessura equivalente, é possível determinar o TRF com o Quadro 1, elaborado pela BIA a partir de resultados experimentais. Interpolando o valor de espessura equivalente, obtém-se o TRF do sistema.

\section{Resultados}

\section{Análise experimental}

Os ensaios de resistência ao fogo foram realizados em dias diferentes. A amostra 1, com $14 \mathrm{~cm} \mathrm{de}$ espessura, teve temperatura inicial de ensaio $\left(T_{0}\right)$ de $19,1^{\circ} \mathrm{C}$, e a amostra 2 , com $19 \mathrm{~cm}$ de espessura, contou com uma temperatura inicial $\left(T_{0}\right)$ de 15,0 ${ }^{\circ} \mathrm{C}$. Ambos os ensaios duraram $240 \mathrm{~min}$, e as manifestações registradas estão apresentadas na Figura 8.

\section{Isolamento térmico}

As Figuras 9 e 10 apresentam os registros de temperatura na face não exposta às elevadas temperaturas das amostras 1 e 2 respectivamente.

Os termopares TP06, TP08 e TP12 se desprenderam da superfície da amostra 1 durante o ensaio e, portanto, foram desconsiderados no cálculo da temperatura média da face externa. Verifica-se que o limite médio dos termopares de $159,1{ }^{\circ} \mathrm{C}$ foi atingido aos $76,00 \mathrm{~min}$ de ensaio, enquanto o limite máximo de $199,18{ }^{\circ} \mathrm{C}$ foi atingido aos $81,00 \mathrm{~min}$.

No ensaio realizado com a amostra 2 verifica-se que o termopar TP10 se desprendeu no decorrer do ensaio e foi desconsiderado no cálculo da temperatura média na face externa da amostra. $\mathrm{O}$ limite médio dos termopares de $155,99{ }^{\circ} \mathrm{C}$ foi atingido aos $115,00 \mathrm{~min}$ de ensaio, enquanto o limite máximo de $195,99{ }^{\circ} \mathrm{C}$ foi atingido aos $150,00 \mathrm{~min}$. 
Figura 7 - Detalhe da verificação da estanqueidade e estabilidade da amostra

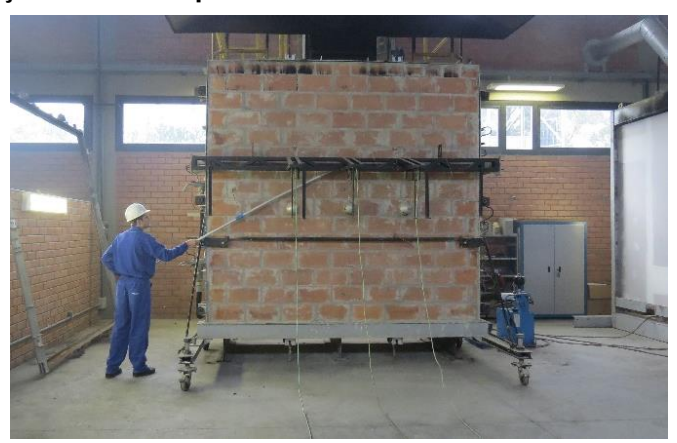

Quadro 1 - Espessuras mínimas equivalentes para alvenarias cerâmicas

\begin{tabular}{|c|c|c|c|c|}
\hline \multirow{2}{*}{ Material } & \multicolumn{5}{|c|}{ Espessura mínima equivalente (mm) para o TRF } \\
\cline { 2 - 5 } & $\mathbf{6 0} \mathbf{~ m i n}$ & $\mathbf{1 2 0}$ min & $\mathbf{1 8 0}$ min & $\mathbf{2 4 0}$ min \\
\hline Bloco maciço & 69 & 97 & 124 & 152 \\
\hline Bloco vazado & 58 & 86 & 109 & 127 \\
\hline Bloco vazado preenchido & 76 & 112 & 140 & 168 \\
\hline
\end{tabular}

Fonte: adaptado de BIA (BRICK..., 2008).

Figura 8 - Manifestações registradas nos ensaios de resistência ao fogo

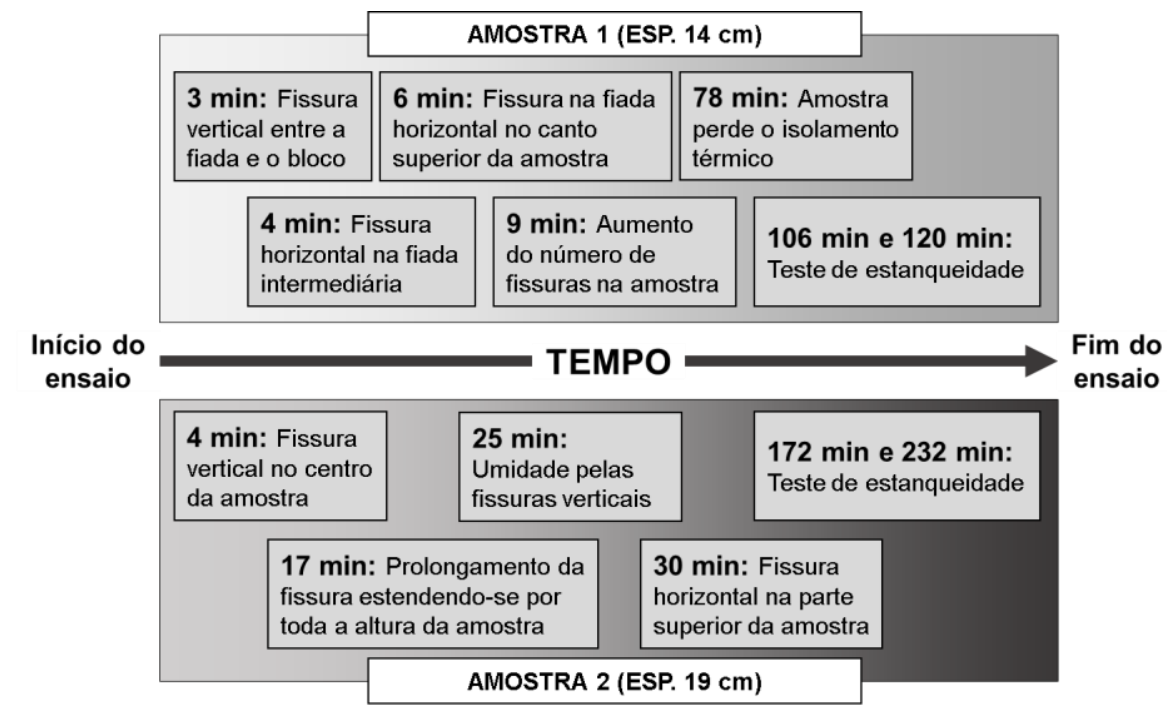

Figura 9 - Temperatura na face externa da amostra 1

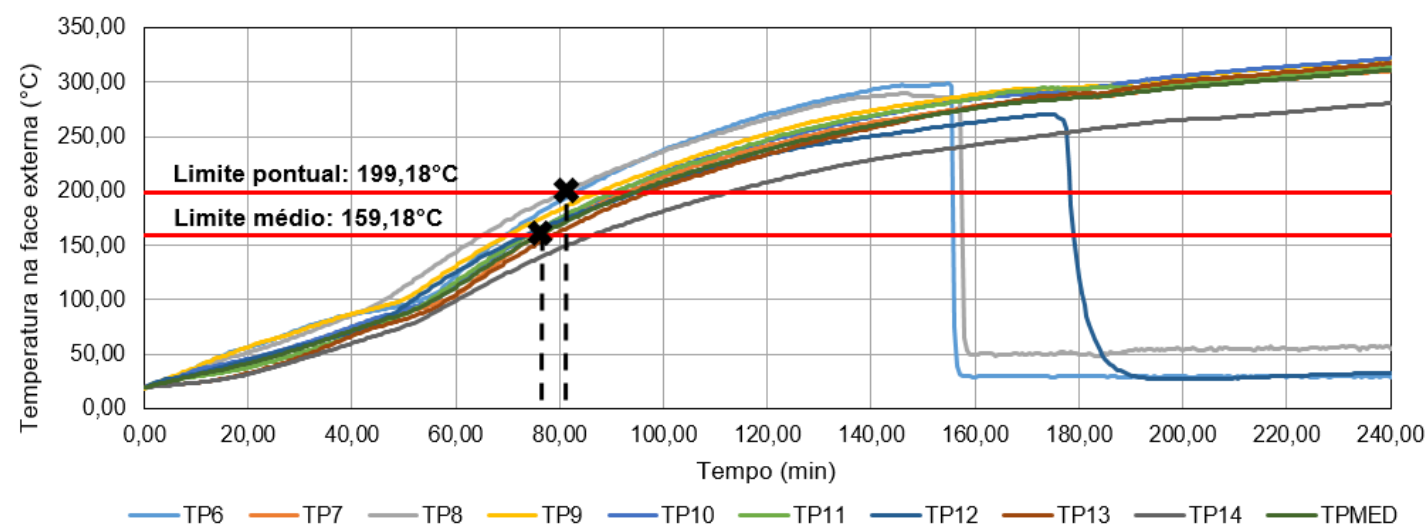

190 Hennemann, G. G.; Gil, A. M.; Fernandes, B.; Bolina, F. L.; Tutikian, B. F. 
Figura 10 - Temperatura na face externa da amostra 2

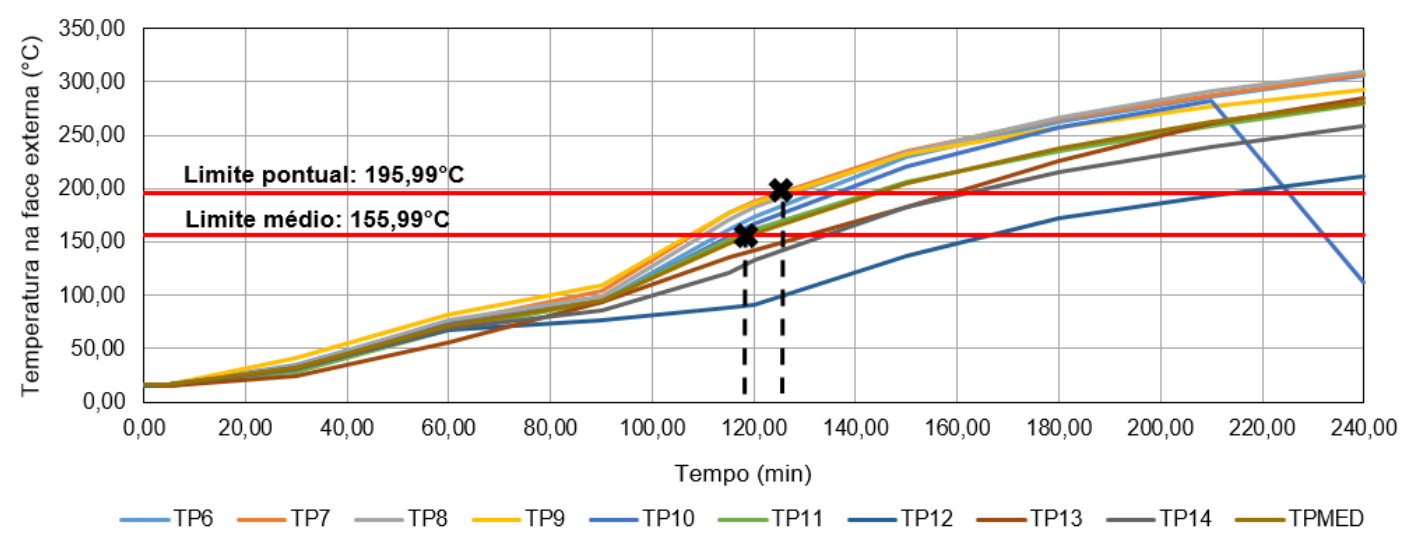

Analisando-se as curvas de temperatura dos dois ensaios, é possível verificar que ambas as amostras apresentam aumento na taxa de aquecimento instantes após ultrapassar a temperatura de $100^{\circ} \mathrm{C}$. Tal comportamento está relacionado ao término da evaporação da água de composição dos materiais empregados.

O Quadro 2 apresenta as imagens obtidas com a câmera termográfica durante os ensaios de resistência ao fogo, registradas de acordo com o acréscimo de temperatura das amostras. As imagens servem de auxílio na identificação de fissuras para a realização dos testes de estanqueidade e do gradiente térmico entre os componentes para verificação de seu comportamento durante o ensaio.

\section{Estanqueidade}

Verificou-se o surgimento da primeira fissura na amostra 1 aos 3 min de ensaio, sucedida por outras de menor magnitude, enquanto a amostra 2 apresentou sua primeira fissura aos $4 \mathrm{~min}$ de ensaio. Procedeu-se à realização do teste de estanqueidade quando as amostras apresentaram liberação excessiva de fumaça e elevados gradientes térmicos, porém em nenhum caso houve a inflamação do chumaço de algodão, o que caracterizou a amostra como estanque. As duas paredes não produziram durante $\mathrm{o}$ incêndio aberturas capazes de propagar gases quentes para o cômodo adjacente.

\section{Estabilidade estrutural}

A Figura 11 apresenta a variação da deformação das amostras durante os ensaios de resistência ao fogo em função do tempo.

Verifica-se que aos $40 \mathrm{~min}$ a amostra 1 apresentou uma deformação horizontal de $30 \mathrm{~mm}$, enquanto a amostra 2 apresentou $22 \mathrm{~mm}$. Ambas as amostras tiveram as deformações ocorridas no decorrer do ensaio diminuídas para o interior do forno, sendo que a amostra 2 retrocedeu $9 \mathrm{~mm}$ para dentro do forno ao término do ensaio. A amostra 1 teve um novo ciclo de deformação, que alcançou novamente $30 \mathrm{~mm}$ aos $180 \mathrm{~min}$ de ensaio, retrocedendo $11 \mathrm{~mm}$ quando o ensaio foi encerrado.

Observa-se que a amostra 1, de menor espessura, apresentou deformação mais rápida e de maior amplitude quando comparada à amostra 2. Tal comportamento pode ser explicado pelo fato de a amostra 1 possuir menor massa volumétrica e menor inércia, o que a torna mais susceptível às deformações térmicas causadas pelo aquecimento, além de uma temperatura média do sistema maior. Constatou-se ainda que, mesmo após o teste mecânico das esferas metálicas, as amostras não apresentaram comprometimento da estabilidade estrutural, garantindo a segurança estrutural.

\section{Aspecto final}

A Figura 12 apresenta o aspecto final da face das amostras exposta às elevadas temperaturas após os ensaios, onde é possível verificar a ocorrência do desplacamento em alguns pontos da amostra 1. O aspecto e a coloração dos dois tipos de blocos após os ensaios foram muito similares, apresentando cor escura e aspecto queimado. 
Quadro 2 - Imagens da câmera termográfica nos ensaios de resistência ao fogo

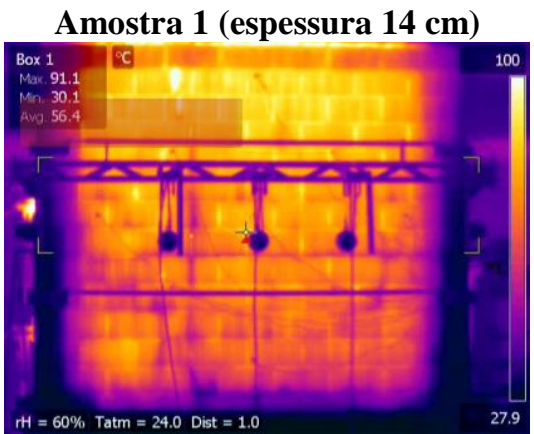

Acréscimo de temperatura aos $30 \mathrm{~min}$

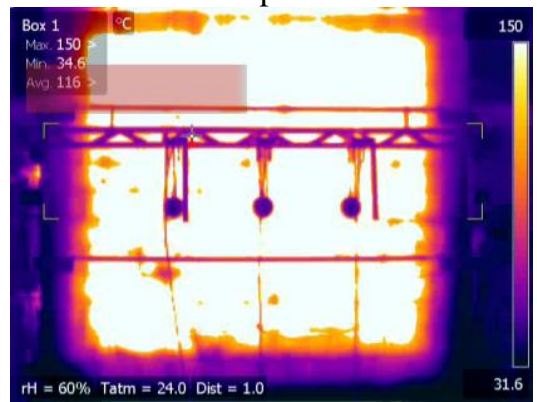

Acréscimo de temperatura aos $70 \mathrm{~min}$

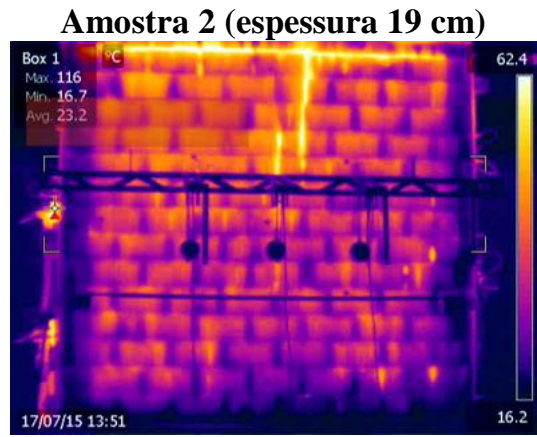

Acréscimo de temperatura aos $22 \mathrm{~min}$

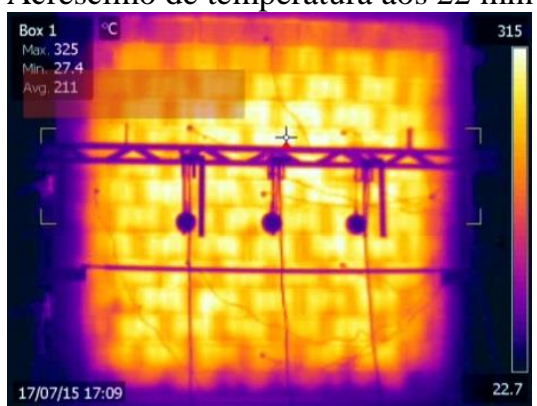

Acréscimo de temperatura aos $220 \mathrm{~min}$

Figura 11 - Deformação horizontal das amostras

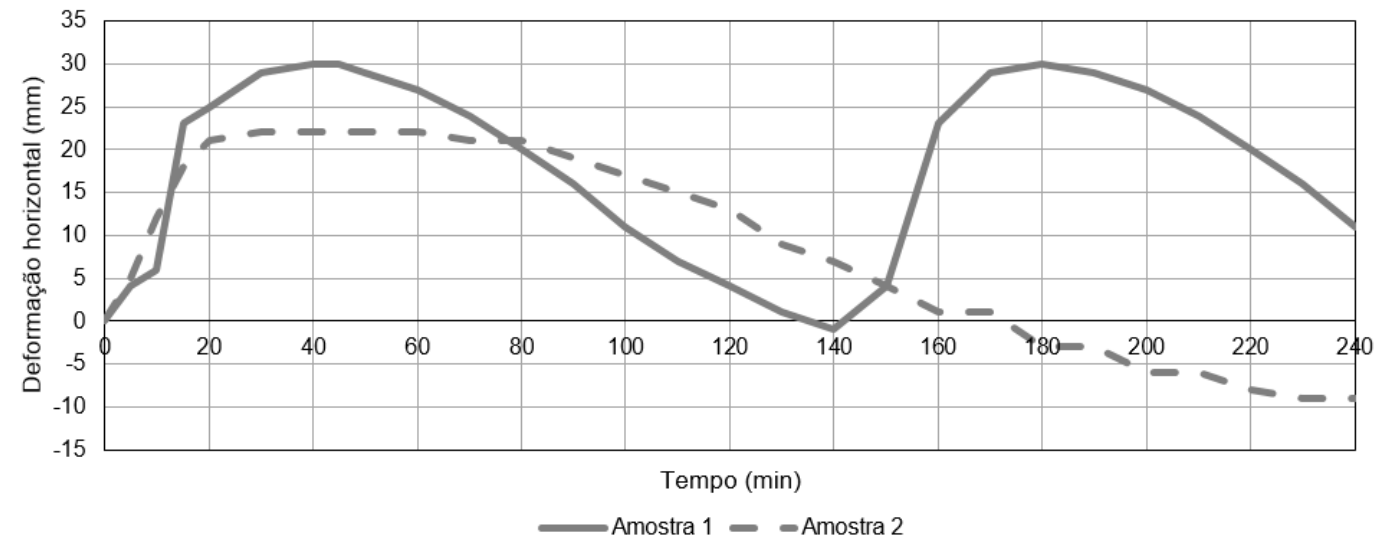

Figura 12 - Aspecto final das amostras: (a) bloco de $14 \mathrm{~cm}$ e (b) bloco de $19 \mathrm{~cm}$

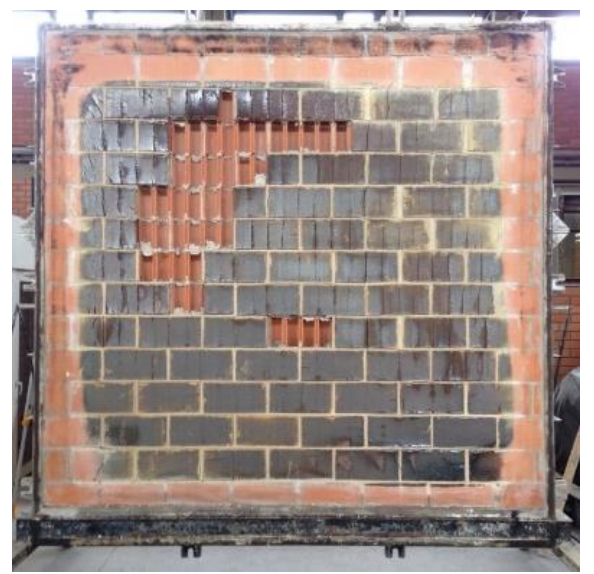

(a)

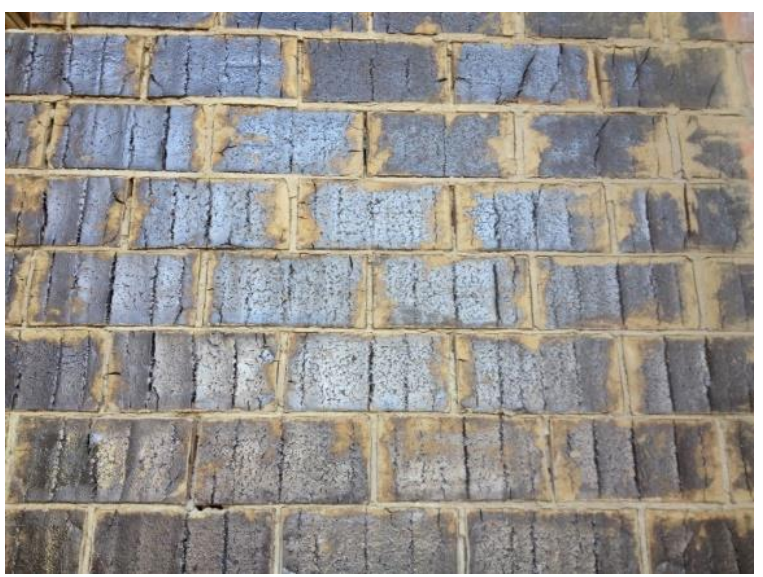

(b)

192 Hennemann, G. G.; Gil, A. M.; Fernandes, B.; Bolina, F. L.; Tutikian, B. F. 
Tabela 1 - Comparação entre resultados experimentais e teóricos

\begin{tabular}{c|c|c|c}
\hline \multirow{2}{*}{ Alvenaria } & \multicolumn{3}{|c}{$\begin{array}{c}\text { Tempo de resistência ao fogo } \\
\text { (Critério isolamento térmico) }\end{array}$} \\
\cline { 2 - 4 } & $\begin{array}{c}\text { Experimental } \\
\text { (min) }\end{array}$ & $\begin{array}{c}\text { Teórico (BIA) } \\
\text { (min) }\end{array}$ & $\begin{array}{c}\text { Diferença } \\
(\%)\end{array}$ \\
\hline $14 \mathrm{~cm}$ & 76 & 46,7 & 38,5 \\
$19 \mathrm{~cm}$ & 115 & 98,6 & 14,3 \\
\hline
\end{tabular}

\section{Análise teórica}

A análise teórica realizada pelo método da BIA é apresentada na sequência. As primeiras etapas, de cálculo da espessura equivalente das alvenarias de $14 \mathrm{~cm}$ e $19 \mathrm{~cm}$, são demonstradas nas Equações 3 e 4 respectivamente. Ressalta-se que, por não apresentar revestimentos interno e externo, a única parcela para o cálculo da espessura é a relativa ao bloco.

$E e_{(14 \mathrm{~cm})}=0+[140 \times(1-0,63)]+0=$ $51,8 \mathrm{~mm}$ Eq. 3

$E e_{(19 \mathrm{~cm})}=0+[190 \times(1-0,60)]+0=$ $76,0 \mathrm{~mm}$

Eq. 4

Ao interpolar os valores obtidos com os estabelecidos na Tabela 1, obtém-se que o TRF da amostra 1 é de 46,7 min e que o TRF da amostra 2 é de 98,6 min. Esses valores foram comparados com o instante em que as alvenarias perderam o isolamento térmico na análise experimental (Tabela 1), visto que a metodologia do BIA leva em consideração apenas este critério.

Observa-se que os valores teóricos apresentam diferenças de até $38,5 \%$ menores que os obtidos experimentalmente. Esse comportamento também foi observado por Rosemann (2011), que verificou diferenças de até 29\%. Ressalta-se que essa diferença está diretamente ligada ao fato de o método proposto pela BIA ser baseado em ensaios realizados em blocos com materiais constitutivos diferentes dos aplicados no presente programa experimental (ROSEMANN, 2011). Além disso, por ser um método numérico, algum grau de conservadorismo está intrínseco ao método. Nguyen et al. (2009) destacam a dificuldade de extensão de resultados experimentais para outros sistemas devido às complexidades e singularidades de cada tipo de alvenaria.

\section{Conclusão}

Foram avaliados dois sistemas de vedação vertical de alvenaria, em escala real, compostos de blocos cerâmicos com espessuras diferentes $(14 \mathrm{~cm}$ e 19 $\mathrm{cm})$, expostos à curva de incêndio padrão da ISO 834. Para tanto foram realizados dois ensaios experimentais de resistência ao fogo em escala real, cujos resultados foram comparados com o método teórico proposto pela BIA. Os ensaios foram realizados seguindo as prescrições das principais normas internacionais.

Ambas as amostras ensaiadas mantiveram suas características de estabilidade e estanqueidade durante os $240 \mathrm{~min}$ de ensaio. Por outro lado, verificou-se perda de isolamento térmico das duas amostras durante o ensaio. A diferença de tempo que cada sistema levou para atingir o limite de temperatura foi de aproximadamente $45 \mathrm{~min}$.

Pode-se concluir que a espessura da alvenaria exerce influência em sua resistência ao fogo e governa o desempenho das paredes de alvenaria pelo critério de isolamento térmico. $\mathrm{O}$ aumento da espessura da alvenaria em $5 \mathrm{~cm}$ pode levar ao aumentar do tempo de resistência ao fogo em mais de $30 \%$ experimentalmente ou em mais de $50 \%$ pelo método teórico. Verifica-se que a diferença entre os resultados obtidos pelo método teórico e pelo método experimental pode superar $30 \%$, em que o método teórico se mostra mais conservador, principalmente para os sistemas com menor espessura, com um grau de conservadorismo bem evidente. Ambos os sistemas podem ser utilizados para edificações habitacionais que seguem a ABNT NBR 15575:2013, porém cada qual com seu campo de aplicação.

\section{Referências}

AL-HADHRAMI, L. M.; AHMAD, A.

Assessment of Thermal Performance of Different Types of Masonry Bricks Used in Saudi Arabia. Applied Thermal Engineering, v. 29, p. 11231130, 2009.

AMERICAN SOCIETY FOR TESTING AND MATERIALS. E 119: standard test methods for fire tests of building construction and materials. West Conshohocken, 2014.

ANDREINI, M. et al. Mechanical Behavior of Masonry Materials at High Temperatures. Fire and Materials, v. 39, n. 1, p. 41-57, 2015. 
ASSOCIAÇÃO BRASILEIRA DE NORMAS TÉCNICAS. NBR 10636: paredes divisórias sem função estrutural: determinação da resistência ao fogo: método de ensaio. Rio de Janeiro, 1989.

\section{ASSOCIAÇÃO BRASILEIRA DE NORMAS} TÉCNICAS. NBR 14432: Exigências de resistência ao fogo de elementos construtivos de edificações: procedimento. Rio de Janeiro, 2001.

\section{ASSOCIAÇÃO BRASILEIRA DE NORMAS} TÉCNICAS. NBR 15575: edificações

habitacionais: desempenho. Rio de Janeiro, 2013.

AUSTRALIAN STANDARD. AS 1530: methods for fire tests on building materials, componentes and structures. Sidney, 2005.

AYALA, R. Mechanical Properties and Structural Behaviour of Masonry at Elevated Temperatures. Thesis - Universidade de Manchester, Manchester, 2011.

BRICK INDUSTRY ASSOCIATION. Tchnical Note 16: fire resistance of brick masonry. Reston, 2008.

BRITISH STANDARD. BS 476-3: fire tests on building materials and structures. Classification and method of test for external fire exposure to roofs. Londres, 2004.

CHICHIERCHIO, L. C. Conforto Ambiental: desempenho térmico e acústico e proteção contra fogo. In: ASSOCIAÇÃO BRASILEIRA DA CONTRUÇÃO INDUSTRIALIZADA. Manual Técnico de Alvenaria. São Paulo: ABCI, 1990.

COSTA, C. N.; SILVA, V. P. Revisão Histórica das Curvas Padronizadas de Incêndio. In: SEMINÁRIO INTERNACIONAL NUTAU, São Paulo, 2006. Anais... São Paulo, 2006.

INGHAM, J. P. Application of Petrographic Examination Techniques to the Assessment of Fire-Damaged Concrete and Masonry Structures. Materials Characterization, v. 60, n. 7, p. 700709, 2009.

\section{INTERNATIONAL ORGANIZATION FOR} STANDARDIZATION. ISO 834-8: fire resistance tests: elements of building construction: part 8 : specific requirements for non-loadbearing vertical separating elements. Switzerland, 2014.

KLEIN, D. L. et al. Análise da Transmissão de Calor em Paredes de PVC Recheadas Com Concreto e em Alvenaria de Blocos Cerâmicos Maciços e Vazados. In: JORNADAS ARGENTINAS DE INGENIERÍA ESTRUCTURAL, 18., Buenos Aires, 2004. Anales... Buenos Aires, 2004.
NADJAI, A.; O'GARRA, M.; ALI, F. Finite Element Modelling of Compartment Masonry Walls in Fire. Computers \& Structures, v. 81, n. 18, p. 1923-1930, 2003.

NGUYEN, T. D. et al. The Behaviour of Masonry Walls Subjected to Fire: modelling and parametrical studies in the case of hollow burntclay bricks. Fire Safety Journal, v. 44, n. 4, p. 629-641, 2009.

NGUYEN, T. D.; MEFTAH, F. Behavior of Clay Hollow-Brick Masonry Walls During Fire: part 1: experimental analysis. Fire Safety Journal, v. 52, p. 55-64, 2012.

NGUYEN, T. D.; MEFTAH, F. Behavior of Hollow Clay Brick Masonry Walls During Fire: part 2: 3D finite element modeling and spalling assessment. Fire Safety Journal, v. 66, p. 35-45, 2014.

RIGÃO, A. O. Comportamento de Pequenas Paredes de Alvenaria Estrutural Frente a Altas Temperaturas. Santa Maria, 2012. Dissertação (Mestrado em Engenharia Civil) - Programa de Pós-Graduação em Engenharia Civil e Ambiental, Universidade Federal de Santa Maria, Santa Maria, 2012.

ROMAN, H. R. Características Físicas e Mecânicas que Devem Apresentar os Tijolos e Blocos Cerâmicos para Alvenaria de Vedação e Estrutural. In: SIMPÓSIO DE DESEMPENHO DE MATERIAIS E COMPONENTES DE CONSTRUÇÃO CIVIL, 3., Florianópolis, 1991. Anais... Florianópolis: UFSC, 1991.

ROSEMANN, F. Resistência ao Fogo de Paredes de Alvenaria Estrutural de Blocos Cerâmicos Pelo Critério de Isolamento Térmico.

Florianópolis, 2011. Dissertação (Mestrado em Engenharia Civil) - Programa de Pós-Graduação em Engenharia Civil, Universidade Federal de Santa Catarina, Florianópolis, 2011.

RUSSO, S.; SCIARRETTA, F. Experimental and Theoretical Investigation on Masonry After High Temperature Exposure. Experimental Mechanics, v. 52, n. 4, p. 341-359, 2012.

SÃO PAULO. Secretaria de Estado dos Negócios da Segurança Pública. Polícia Militar. Corpo de Bombeiros. Instrução Técnica n. 8: resistência ao fogo dos elementos de construção. São Paulo, 2011.

SILVA, V. P. Projeto de Estruturas de Concreto em Situação de Incêndio: conforme ABNT NBR 15200:2012. São Paulo: Blucher, 2012. 
THOMAZ, E.; HELENE, P. Qualidade no

Projeto e na Execução de Alvenaria Estrutural

e de Alvenaria de Vedação em Edifícios. São

Paulo: Epusp, 2000.

\section{Guilherme Günther Hennemann}

itt Performance | Universidade do Vale do Rio dos Sinos | Av. Unisinos, 950, São João Batista | São Leopoldo - RS - Brasil | CEP $93022-000$ | Tel.: (51) 3590-8887 Ramal 3291 | E-mail: guilhermeghennemann@gmail.com

\section{Augusto Masiero Gil}

itt Performance, Programa de Pós-Gradução em Engenharia Civil | Universidade do Vale do Rio dos Sinos | Tel.: (051) $3590-8887$ Ramal 3293 | E-mail: augustomg@unisinos.br

\section{Bruno Fernandes}

Departamento de Estruturas | Universidade Estadual de Campinas | Rua Saturnino de Brito, 224, Cidade Universitária Zeferino Vaz | Campinas - SP - Brasil | E-mail: fernandes.brn@gmail.com

\section{Fabrício Longhi Bolina}

itt Performance, Programa de Pós-Gradução em Engenharia Civil | Universidade do Vale do Rio dos Sinos | Tel.: (51) 3590-8887 Ramal 3291 | E-mail: fabriciobolina@gmail.com

Bernardo Fonseca Tutikian

itt Performance, Mestrado Profissional em Arquitetura e Urbanismo, Programa de Pós-Gradução em Engenharia Civil | Universidade do Vale do Rio dos Sinos | Tel.: (51) 3591-1122 | E-mail: bftutikian@unisinos.br

\section{Revista Ambiente Construído}

Associação Nacional de Tecnologia do Ambiente Construído

Av. Osvaldo Aranha, $99-3^{\circ}$ andar, Centro

Porto Alegre - RS - Brasil

CEP $90035-190$

Telefone: +55 (51) 3308-4084

Fax: +55 (51) 3308-4054

www.seer.ufrgs.br/ambienteconstruido

E-mail: ambienteconstruido@ufrgs.br 